\title{
Think Global, Act Local: Using the Internet to Facilitate Transformative Learning in Regional Universities
}

\author{
Ann-Marie Priest, Division of Teaching and Learning Services, Central Queensland \\ University, Australia (a.priest@cqu.edu.au)
}

This article has been anonymously peer-reviewed and accepted for publication in the International Journal of Pedagogies and Learning, an international, peer-reviewed journal that focuses on issues and trends in pedagogies and learning in national and international contexts. ISSN 1833-4105.

(C) Copyright of articles is retained by authors. As this is an open access journal, articles are free to use, with proper attribution, in educational and other non-commercial settings.

\begin{abstract}
The recent increase in the number of international students in the Australian higher education system has dramatically affected the ways in which regional universities understand their identity and mission. No longer focused primarily on their local regional communities, such institutions are now involved in negotiating the problematic relationships between, and the multiple identities of, the global and the local in their classrooms, both physical and virtual. This paper identifies ways in which regional universities can use online learning as a tool for transformation of all their students, wherever they are located, and, by extension, of their own regional, national and international communities.
\end{abstract}

\section{Introduction}

Over the past two decades, there has been a huge increase in the number of international students enrolled in Australian universities. From a small base, enrolments grew 1,041 per cent between 1980 and 1999 (Welch, 2002, p. 442). There has been a strong financial imperative for this growth; as Welch (2002, pp. 443-444) points out, the rise in international student numbers has accompanied, and been at least partly driven by, a dramatic decline in federal funding for higher education in Australia. But the benefits of increasing internationalisation for the staff and students of Australian universities as well as for the Australian community more generally are manifold. In an increasingly globalised job market, exposure to diverse social and cultural contexts enables students to develop skills, attitudes and outlooks that will stand them in good stead in their professional lives (McLoughlin, 2001, p. 11; Rizvi, 2000 , p. 223). Further, evidence suggests that diverse learning environments facilitate learning (Boylan, 2002; McLoughlin, 2001). Perhaps even more importantly, the presence of international students can transform local communities. As Rizvi argues, "Their presence contributes to the creation of 'in-between' cultural spaces not bounded by the dictates of geography. They reconstitute localities by their mere presence" (2000, p. 209).

The growth in international student numbers has particularly powerful implications for Australia's regional universities, both in economic terms, as a means of surviving government funding cuts to higher education, and in social and educational terms. Traditionally, regional universities have understood their identity and mission specifically in terms of local and regional students. The commitment of many such institutions to distance education has reflected this conception of their identity and mission as providers of higher education to people in remote and regional areas. But the growth in international student numbers has expanded that identity and mission 
exponentially. 'Town and gown in the bush' no longer refers solely to the relationship between a regional university and the local communities in which it physically operates but encompasses communities - both metropolitan and regional - in other nations. This expansion of the way that regional universities conceive of themselves is necessary for their economic survival. But it also offers new and unique opportunities for these institutions to transform both their traditional local communities and the new communities with which their international students bring them into relationship.

Currently, however, the full potential of such transformations is not always being realised. In a number of regional institutions, international students are geographically removed from the local students of their own institution. Concentrated in purpose built campuses in metropolitan areas, international students have often only a shadowy presence in the regions. This means that the experience of internationalisation is limited for both Australian regional and (to a lesser extent) international students, and the potential for the participation of regional students, in particular, in what Rizvi (2000, p. 223) calls a "new global generation" is curtailed. Use of the Internet, however, can foster collaboration among culturally diverse individuals (Burbules, 2000; McLoughlin, 2001; Welch, 2002). This paper argues that the use of the Internet in teaching and learning has the potential to bring local and international students together in learning communities in which not only knowledge but also identities can be constructed and reconstructed through meaningful collaboration. The use of the Internet does not in itself guarantee such collaboration; a focus on educational, rather than economic, imperatives and the use of a dialogic rather than a didactic approach to online teaching and learning are also required. But the result - the creation of virtual learning communities that bring together local and international students - has the potential to subvert the global-local dichotomy. The goal of both local and international students is the same: to negotiate their own relationship to the global in a way that is positively transformative. Online collaboration can provide a way of enabling local students to gain global experience while allowing international students to experience the local anew.

\section{Local Versus Global: Who is What?}

The intersection of the global and the local is often problematised in theories of globalisation. As Kellner (2000) writes: "For its critics...globalization is bringing about the devastating destruction of local traditions, the continued subordination of poorer nations and regions by richer ones, environmental destruction, and a homogenization of culture and everyday life" (p. 302). But, as Kellner goes on to argue, globalisation is more complex in its effects than these criticisms seem to allow. The challenge as Kellner sees it is not to focus on one side or the other of the globallocal dichotomy but to think through the relationships between the global and the local by observing how global forces influence and even structure an increasing number of local situations. One should also see how local forces mediate the global, inflecting global forces to diverse ends and conditions and producing unique configurations of the local and the global as the matrix for thought and action in the contemporary world (p. 309).

References to the 'McDonaldisation' of the world point to the potential of globalisation to create an entirely homogeneous world by obliterating local cultures (Burbules \& Torres, 2000). But they also suggest that local communities are the helpless victims of Western neocolonialism. As Rizvi (2000) and Luke and Luke 
(2000), among others, point out, this is far from the case. Writing from an Australian perspective, Luke and Luke (2000) argue that the "flows" between the global and the local are by no means straightforwardly one way. They posit instead:

...the two-way, mutually constitutive dynamics of local-global flows of knowledge, power, and capital, of systematic as well as unsystematic and uneven 'effects,' and of local histories that always embed 'the new' in existing and generative material-economic and cultural conditions. (p. 276)

Luke and Luke's (2000) argument is that "the local" is not simply a site for the receipt and reproduction of Western cultural programming but rather a space of contestation and reconstruction in which cultural products may be transformed. They acknowledge the "hegemonic effects of fast capitalist consumption and production", but seek to "offer a counterpoint by arguing that homogenizing effects are always rearticulated in social fields where they are subject to local and regional force and power" (p. 276).

Australia's position within this global-local dynamic is a complex one. Despite its geographical location in Asia, Australia is considered to be a part of the West as a result of its historical links with Britain and its current cultural, political and economic links with the United States of America. It is therefore nominally a part of the juggernaut that is spreading Western cultural and economic values around the globe. Indeed, its Western identity has been crucial to the success of Australian universities in attracting international students from Asia. As Rizvi's (2000) research demonstrates, some international students (his research focuses on students from Malaysia) come to Australia to study specifically because it offers them a Western education, which they believe is a more marketable commodity than a local education in both their own local and the global job market.

Nevertheless, Australia's position as a Western nation is in many ways a marginal one. As Luke and Luke (2000) point out, Australia's "relatively isolated location on the globe in the 'far south' and 'far east' situates us very much on the geopolitical and cultural margins", and our major cities "must work very hard to represent themselves as world cities worthy of participation in global capital and information flows" (p. 277). What's more, there is a strong sense within Australia that an Australian culture exists that is quite distinct from both British and United States culture - a culture that is worth preserving, as the recent debate about the Free Trade Agreement has demonstrated (see for example Rundle, 2003). Many Australians feel themselves to be not the purveyors but the victims of the homogenising effects of global (read: United States) culture.

To complicate this picture further, Australia is itself far from homogeneous, containing diverse regions which define themselves as local in relation to metropolitan centres (particularly capital cities). These local, or regional, communities are often regarded as disadvantaged (marginal), experiencing lower socioeconomic status and income than their metropolitan counterparts, lower participation rates in higher education and relatively poorer infrastructure (Winchester, Glenn, Thomas \& Cole, n.d., pp. 2-3). Local students at a regional Australian university, then, are in some ways unlikely neocolonisers. Their relationship to international students whose home cultures are themselves 'local' in relation to global culture is by no means a straightforward one. 


\section{International Education at Regional Universities}

Part of the rationale for the existence of regional universities in Australia is that they redress the perceived disadvantage suffered by local students. They offer "students in the regions the opportunity to study within easy access of their families and support structures" and create "opportunities" and "employment" that "help to keep the regions alive" (Winchester, Glenn, Thomas \& Cole, n.d., p. 3). By design, then, Australia's regional universities have traditionally had strong links with their regional communities. As well as their "traditional core business of educating local students", many regional universities see their ties to the local/regional economy as an intrinsic part of their strategic direction (Garlick, 1998, p. 18). Historically, a number of regional universities developed strong distance education programs as part of their commitment to remote and isolated students in their regions and throughout Australia. As Tickle, Clayton and Hawkins (2003) explain, however, recent changes in the political climate of higher education have had an impact on the ways in which regional universities relate to their regions: "the reduction in government funding, the loss of exclusivity for distance education providers and increased competition for students forced many such institutions to look at different strategies to ensure survival" (pp. 1-2). One such strategy was to increase the number of full fee-paying international students.

This move had - and still has — the potential to challenge the traditional raison d'être of regional universities: to provide educational opportunities for their local populations. In expanding their focus to include international students, regional universities run the risk of becoming organisations that are oblivious to their local environment, organisations that, as Garlick (1998) puts it, "go about their own private business with a dilettante attitude toward the community of place they are in and with an outlook of being more in the community than of it" (p. 15; emphasis in original). Certainly, the growth of international student numbers in regional universities has created more organisational complexity, multiplying the number of communities in which, and with which, each university operates. Central Queensland University (CQU) is a case in a point. It has regional campuses at Rockhampton (the university's home campus), Mackay, Bundaberg, Gladstone and Emerald in Central Queensland, and purpose built campuses catering specifically for international students at Sydney, Melbourne, Brisbane and the Gold Coast, known within CQU as the Australian International Campuses (AICs). It also has teaching operations in Hong Kong, Singapore and Chengdu. While there are some international students at the regional campuses, three quarters of CQU's international students study at the AICs (Tickle, Clayton \& Hawkins, 2003, p. 2).

If, as Welch (2002) suggests, internationalisation in Australian universities has largely been driven by "the forces of global economic restructuring" (p. 445), the appeal of an Australian education for international students seems to lie in a social commitment to globalisation. Rizvi's (2000) study of Malaysian students in Australia identifies a number of reasons for their decision to travel to Australia for their education, but emphasises the value that these students placed on what they called "exposure":

The term 'exposure' appeared a great deal in the discourses of the Malaysian students. Exposure to things foreign - to different people and cultures, to different ideas and attitudes, and to different ways of learning and working-is a feature common in all our interviews. (p. 214) 
Such exposure was seen not only as making the students more marketable as graduates, but also as a desirable part of each student's own personal development. It enabled them to develop what one student called a "global imagination", a concept that Rizvi (2000) explains both as a "romantic vision of a world in which people around the world were connected with each other" (p. 218) and also as the capacity to "imagine the nation and its links to the outside world in radically new ways" (p. 223). For Rizvi, the experience of being an international student is beneficial in terms not only of the students' future employability but also of their personal identity:

With formative international experiences, they are able to look at the world as dynamic and multicultural. This is so because they operate within a hybridized space and are equally comfortable in more than one cultural site. Their identity is intercultural with multiple cultural defining points. They typify a new global generation. (p. 223)

Ideally, the development of a "global imagination" would be facilitated not only among international students, who are gaining a global perspective through international study, but also among local students through both the internationalisation of the curricula of their local universities and their interactions with students from other cultures. Indeed, as McLoughlin (2001) points out, the United Nations Educational, Scientific and Cultural Organisation has reported on "the need to broaden the higher education experience of the majority of students who will not travel or at least will not be able to study in another country" (p. 11). One way of doing this, she suggests, is through the notion of "multicultural education", which includes "fostering understanding of human diversity, commonality and social justice, while promoting intercultural competencies" (p. 12).

McLoughlin (2001) argues that the attributes associated with a multicultural education - "an understanding of cultural and social diversity, with the capacity to work effectively in diverse communities or with people who may have very different life experiences and world views" (p. 11) — are increasingly sought by employers both in Australia and overseas. She also cites research that shows that "students who learn in an environment where multiple and diverse perspectives are fostered and appreciated become better critical thinkers, better communicators, better problem-solvers and better team players" (p. 11). Certainly an increasing body of literature has shown that, as Boylan (2002) points out, the experience of diversity contributes to students' cognitive development: "Having the opportunity to interact with students from different ethnic backgrounds has a statistically significant positive impact on critical thinking scores among college students" (p. 8). Further, "the greater the ethnic diversity of the college classroom, the greater the cognitive gains among students in these classrooms" (p. 8). Research in the K-12 classroom similarly suggests that diversity among learning collaborators may contribute to "achievement and productivity, creative problem solving, growth in cognitive and moral reasoning, increased perspective-taking ability, and general sophistication in interacting and working with peers from a variety of cultural and ethnic backgrounds" (Johnson \& Johnson, 1998, p. 68).

All the evidence suggests, then, that regional students have a lot to gain in collaborating in their learning with international students, just as international students have from studying in a different culture. For both sets of students, collaboration would potentially improve their own learning as well as assist in the development of 
desirable skills, attitudes and attributes. Such collaboration also has the potential, less tangibly, to contribute to greater justice and harmony in the world. As Burbules and Torres (2000) suggest, multiculturalism "as a social movement, as citizenship education, and as an antiracist philosophy in curriculum" has the potential to "intervene in the dynamics of social conflict emerging between global transformations and local responses" (p. 21).

But, in order to make such interventions, multiculturalism needs to be something students have a lived experience of, rather than something that is taught through a kind of 'shopping mall' approach to different cultures:

As Vinz makes clear, dominant approaches to multicultural education evidence a kind of market logic, putting multiple and fabricated cultural products at the fingertips of students to consume in very superficial ways. This 'we are the world' approach to education elides the complexity and tension of the emerging global reality, making it one more product for consumers to consume in simple and simply unproductive ways. (McCarthy \& Dimitriades, 2000, p. 192)

In educational interactions among people from diverse backgrounds, however, "the complexity and tension" associated with the coexistence of different cultures are much more difficult to elide. But in the case of regional universities like CQU, the possibilities for such interactions are limited by the tendency to keep international and regional students separate on their own campuses. One way to overcome this separation and begin to create Rizvi's (2000) “'in-between' cultural spaces” (p. 209) is through the use of the Internet for teaching and learning.

\section{Multicultural Interaction, Dialogic Teaching and the Internet}

The Internet is now being used widely for teaching and learning at Australian universities. In 2001, 60\% of courses in Australian universities made some use of the World Wide Web (Bell, Bush, Nicholson, O'Brien \& Tran, 2002, p. x), and the figure has undoubtedly continued to climb. One of the great strengths of the medium is its capacity to facilitate communication, and this has been of particular benefit to institutions in which teaching and learning are distributed across a number of locations. I want to propose that the qualities that make the Internet so suitable for teaching and learning at a distance are the same qualities that, with careful learning design and a commitment to the philosophy of transformative learning, would make the Internet ideal for creating a vibrant international community that is located in between' local and international spaces, as well as between 'town and gown'.

There can be no doubt that there are dangers in the use of the Internet within higher education. As Welch (2002) puts it, "despite the rhetoric about flexible delivery and more creative pedagogies, the global strategy of electronic marketing of higher education is motivated principally by cost considerations" (p. 466). In such a climate, online education can easily become "just another way of dumping course content, with the assumption that all students, regardless of cultural background, can access learning resources and achieve success" (McLoughlin, 2001, p. 8). A focus on the use of the Internet as a specific strategy to develop multicultural education, however, should avoid both of these pitfalls, with the emphasis squarely on pedagogical rather than cost considerations. 
The Internet is widely regarded by educators as particularly suited to teaching and learning activities involving collaboration and interaction. As McLoughlin (2001) points out, the Internet has the potential to create "opportunities for interaction, immediacy, networked learning and communication across borders" (p. 8). Burbules (2000) emphasises that, while the Internet is often seen as "a repository for, or a means for the dissemination of, information", it is also "a medium where collaboration happens and where people can create networks of distributed intelligence" (p. 335). It is an environment that "instantiates collaboration, in which participants can compose themselves as working groups, and where the identity of a working group as a group takes hold" (Burbules, 2000, p. 335; emphasis in original). Although it is evident that the online environment is not as semantically rich as a faceto-face environment, research indicates that there is "evidence that successful collaboration as described in face-to-face situations is possible in online learning environments" (Curtis \& Lawson, 2001, p. 32).

Further, Coomey and Stephenson's (2001) investigation of research into online teaching and learning suggests that the online mode facilitates "a migration from traditional didactic modes to more learner-managed learning modes if teachers and designers wish to take such a journey" (p. 49). For them, the keys to effective online teaching and learning identified in the literature are "structuring the learning activity and designing the materials in order to promote dialogue, secure active involvement of the learner, provide personal or other support and feedback and enable the learner to exercise the degree of control expected" (p. 38; emphasis in original). They go on to emphasise that dialogue does not happen automatically but needs to be structured into an online course: "Instructors and course designers, for instance, cannot assume that learners will be able to jump into group discussions, argue in online debates, or answer questions posed online, just because they are told to participate" (p. 39). I would go further and suggest that, if online dialogue is to be truly transformative, it needs not only to be carefully designed in terms of the technology and instructional aspects of the course but also to grow out of a genuine respect for the students and their experience and knowledge.

Such a stance is the basis of theories of liberatory or emancipatory education such as those espoused by Paulo Freire. In Freire's model of dialogic teaching, teachers and students construct knowledge together. For Freire, dialogue is "a moment where humans meet to reflect on their reality as they make and remake it" (Shor \& Freire, 1987, p. 98). The teacher is no longer seen as the possessor of knowledge who, in teaching, makes a gift of that knowledge to the students. Instead, "the object to be known is put on the table between the two subjects of knowing. They meet around it and through it for mutual enquiry" (Shor \& Freire, 1987, p. 99; emphasis in original). This process of "dialogic inquiry" foregrounds the "culture, language, politics, and themes of the students" (Shor \& Freire, 1987, p. 104); in other words, the students' identities, both local and global, are seen not as peripheral but as central to the learning process, and as learning resources both for the individual student and for the class as a whole.

Similarly, Vygotsky's theories of social constructivism, which have been particularly influential in the area of online learning, foreground dialogue as essential to learning, placing: 
...the emphasis on the co-construction of knowledge by more mature and less mature participants engaging in activity together....In the place of competitive individualism, his theory proposes a collaborative community in which, with the teacher as leader, all participants learn with and from each other as they engage together in dialogic inquiry. (Wells, 1999, p. xii)

The desired result, Wells (1999) proposes, is that:

...classrooms should become communities of inquiry, in which the curriculum is seen as being created emergently in the many modes of conversation through which teacher and students dialogically make sense of topics of individual and social significance, through action, knowledge building and reflection. (p. 98)

Wells (1999) is writing specifically about K-12 schooling, but his argument applies equally well to tertiary education conducted online. As Shor and Freire (1987) point out, transformative education does not depend on a particular teaching tool or technology but rather on a specific approach, one which aims to "critically reorient students to society" and "animate their critical thinking" (Freire; cited in Shor \& Freire, 1987, p. 40). Equally crucially, such teaching begins with the language and experience of the students themselves (p. 41).

In a classroom, physical or virtual, in which there are students from many different cultures, entering into the language and experience of the students is a radical move, and one which necessarily involves the teacher in letting go of a certain measure of control. The use of dialogic methods of teaching and learning is by no means widespread in higher education, though it appears to be increasing, in part as a result of research into the most effective pedagogies for use online. In the context of international education, however, it may even be decreasing, owing to certain preconceptions about the preferred teaching and learning styles of international students. Ramburuth and McCormick (2001, p. 335) note that there are many such preconceptions about Asian students, who are often viewed, for example, as "rote learners, relying more on memorization than understanding, adopting more surface approaches to learning, and text-book dependent". Such stereotypes are often reinforced by the teaching strategies that universities employ for international students. Tickle, Clayton and Hawkins (2003), for example, write that international students "bring with them a variety of complex and subtle cultural characteristics...that may include styles of thinking and writing as well as a general unassertive predisposition" (p. 4). Perhaps as a result, they write that in staff development programs for teaching staff on the AICs of CQU, "appropriate (often more didactic) teaching strategies are discussed" (p. 5).

But the idea that more didactic teaching models are needed for international students at a time when the trend in higher education generally is towards more learner-centred and dialogic models raises some important issues about the ways in which Western universities construct international students. Ramburuth and McCormick's (2001) research suggests that there is no significant difference between the way that Asian and Australian students learn. Similarly, Biggs (1996) has shown that many of the preconceptions that Westerners typically have about the learning styles of Confucian heritage learners are in fact misconceptions. In fact, the educational context may be more important than the student's cultural background; as Smith and Smith (1999) argue, "approaches to studying must be interpreted in the educational, institutional 
and cultural contexts within which that study occurs" (p. 67). Certainly dialogic models of teaching tend to be challenging for all students, regardless of cultural background, because they require students to be closely and personally engaged with their learning. Indeed, Shor and Freire (1987) argue that traditional Western educational methods produce an alienation from the whole learning process that is very hard to overcome: "After years in dull transfer-of-knowledge classes, in boring courses filled with sedating teacher-talk, many have become non-participants, waiting for the teacher to set the rules and start narrating what to memorize" (p. 122).

Introducing a dialogic mode of education, then, is not easy. But according to McLoughlin (2001), the key to successful multicultural education lies in "acknowledging and valuing differences,... [and] enabling the values and worldviews of all students to be given expression in teaching and learning" (p. 12). For her, this process is facilitated by the use of "collaborative communicative Web tools and conferencing technologies" (p. 13). There may even be some advantage for non-native English speakers in the use of the Internet for communication:

...many nonnative speakers of English will find it easier to use English in online contexts [rather than face-to-face], where they can type their comments as deliberately as they need to, revise what they have written, and receive feedback on the meaningfulness and efficacy of what they have said. (Burbules, 2000, p. 339)

At CQU, international and local students study exactly the same courses, albeit in different locations, so it is more than possible for shared teaching and learning experiences to occur. Experiments with bringing the two sets of students together online have met with success on a number of criteria. For example, one undergraduate business course at CQU, offered on regional and international campuses and in the distance mode, makes use of the Internet to facilitate group work among students from all campuses and in all modes of study (Windeknecht, 2003). Students from many different nationalities collaborate, using an established framework, to complete a major assignment. The process is not easy, but student feedback about the quality of learning suggests that they find it immensely valuable (Windeknecht, 2003).

\section{Conclusion}

The advantages to both local and international students of interaction and collaboration are evident. It is out of communities comprising regional and international students that the 'knowledge workers' of the future - those who will form part of Rizvi's (2000) "new global generation" (p. 223) — will emerge. Given the geographical separation between local and international students at regional universities, the Internet is one way of creating such communities. For regional students, in particular, online interaction with students from different cultures in the context of teaching and learning may simulate something of the experience of living and studying in another country, enabling them to develop that elusive "global imagination" that characterises successful international students. Certainly this kind of interaction creates the potential for a new set of relationships between the local and the global, mediated improbably by the regional and the marginal. The results may well be transformative for all students. 


\section{References}

Bell, M., Bush, D., Nicholson, P., O’Brien, D., \& Tran, T. (2002). Universities online: A survey of online education and services in Australia. Canberra, ACT: Department of Education, Science and Training.

Biggs, J. (1996). Western misperceptions of the Confucian-heritage learning culture. In D. Watkins \& J. Biggs (Eds.), The Chinese learner: Cultural, psychological, and contextual influences (pp. 45-67). Hong Kong and Melbourne, Vic: Comparative Education Research Centre and Australian Council for Educational Research.

Boylan, H. R. (2002). Graduate attributes: Why and how. Keynote address presented at the $2^{\text {nd }}$ international lifelong learning conference, Rydges Capricorn International Resort, Yeppoon, Qld.

Burbules, N. C. (2000). Does the Internet constitute a global educational community? In N. C. Burbules \& C. A. Torres (Eds.), Globalization and education: Critical perspectives (pp. 323-355). New York: Routledge.

Burbules, N. C., \& Torres, C. A. (2000). Globalization and education: An introduction. In N. C. Burbules \& C. A. Torres (Eds.), Globalization and education: Critical perspectives (pp. 1-26). New York: Routledge.

Coomey, M., \& Stephenson, J. (2001). Online learning: It is all about dialogue, involvement, support and control - according to the research? In J. Stephenson (Ed.), Teaching and learning online: Pedagogies for new technologies (pp. 3752). London: Kogan Page.

Curtis, D. D., \& Lawson, M. J. (2001). Exploring collaborative online learning. Journal of Asynchronous Learning Networks, 5(1), 21-34.

Garlick, S. (1998). "Creative associations in special places": Enhancing the partnership role of universities in building competitive regional economies. Canberra, ACT: Department of Employment, Training and Youth Affairs.

Johnson, D. W., \& Johnson, R. T. (1998). Cultural diversity and cooperative learning. In J. W. Putnam (Ed.), Cooperative learning and strategies for inclusion: Celebrating diversity in the classroom (pp. 67-85). Baltimore, MD: Paul H. Brooks.

Kellner, D. (2000). Globalization and new social movements: Lessons for critical theory and pedagogy. In N. C. Burbules \& C. A. Torres (Eds.), Globalization and education: Critical perspectives (pp. 299-321). New York: Routledge.

Luke, A., \& Luke, C. (2000). A situated perspective on cultural globalization. In N. C. Burbules \& C. A. Torres (Eds.), Globalization and education: Critical perspectives (pp. 275-297). New York: Routledge.

McCarthy, C., \& Dimitriades, G. (2000). Globalizing pedagogies: Power, resentment, and the re-narration of difference. In N. C. Burbules \& C. A. Torres (Eds.), Globalization and education: Critical perspectives (pp. 187-204). New York: Routledge.

McLoughlin, C. (2001). Inclusivity and alignment: Principles of pedagogy, task and assessment design for effective cross-cultural online learning. Distance Education, 22(1), 7-29.

Ramburuth, P., \& McCormick, J. (2001). Learning diversity in higher education: A comparative study of Asian international and Australian students. Higher Education, 42, 333-50.

Rizvi, F. (2000). International education and the production of global imagination. In N. C. Burbules \& C. A. Torres (Eds.), Globalization and education: Critical perspectives (pp. 205-225). New York: Routledge. 
Rundle, G. (2003, December 20). Local drama. The Age.

Shor, I., \& Freire, P. (1987). A pedagogy for liberation: Dialogues on transforming education. South Hadley, MA: Bergin \& Garvey.

Smith, P. J., \& Smith, S. N. (1999). Differences between Chinese and Australian students: Some implications for distance educators. Distance Education, 20(1), 64-80.

Tickle, K. S., Clayton D. J., \& Hawkins, K. G. (2003). Quality management models for international campuses and operations: A case study of a regional university's experience. Paper presented at the Australian universities quality forum, Melbourne, Vic.

Welch, A. (2002). Going global? Internationalising Australian universities in a time of global crisis. Comparative Education Review, 46(4), 433-71.

Wells, G. (1999). Dialogic inquiry: Toward a sociocultural practice and theory of education. Cambridge, UK: Cambridge University Press.

Winchester, H., Glenn, A., Thomas, P., \& Cole, M. (n.d.). The role of universities in the regions. Retrieved January 29, 2004, from http://www.bhert.com/Docs/Role\%20of\%20Unis\%20in\%20Regions.doc

Windeknecht, K. (2003). Just tell me what to do: Group dynamics in a virtual environment. Paper presented at the "Women in Research 10th Anniversary Conference", Central Queensland University, Rockhampton, Qld. 